\title{
One-pot tandem approach for the synthesis of benzimidazoles and benzothiazoles from alcohols
}

\author{
Goravanahalli M. Raghavendra, Ajjahalli B. Ramesha, Cigalli N. Revanna, Kebbahalli N. Nandeesh, \\ Kempegowda Mantelingu *, Kanchugarakoppal S. Rangappa* \\ Department of Studies in Chemistry, University of Mysore, Manasagangotri, Mysore 570006, India
}

\section{A R T I C L E I N F O}

\section{Article history:}

Received 10 June 2011

Revised 5 August 2011

Accepted 7 August 2011

Available online 17 August 2011

\section{Keywords:}

${ }^{\circledR} \mathrm{T} 3 \mathrm{P}$

Benzimidazole

Benzothiazole

$o$-Diaminoarenes

o-Aminothiophenols

\begin{abstract}
A B S T R A C T
Propylphosphonic anhydride $\left({ }^{\circledR} \mathrm{T} 3 \mathrm{P}\right)$ has been demonstrated to be an efficient and mild reagent for the one-pot synthesis of benzimidazoles and benzothiazoles from variety of alcohols. Mild conditions, short reaction time, broad functional group tolerance, low epimerization, easy and quick isolation of the products, excellent chemo selectivity, and excellent yields are main advantages of this procedure. Thus, the present method is utilizing alcohols instead of aldehydes.
\end{abstract}

() 2011 Elsevier Ltd. All rights reserved.
The benzimidazole nucleus is the key building block for a variety of compounds that play crucial role in the activity of a number of biologically important molecules. ${ }^{1}$ Benzimidazole and benzothiazole are important pharmacophores in modern drug discovery. ${ }^{2}$ Benzimidazole and benzothiazole derivatives have several therapeutic applications such as antiulcer, ${ }^{3}$ antihelminthic, ${ }^{3}$ antihypertensive, ${ }^{4}$ anticoagulant, ${ }^{5}$ antiallergic, ${ }^{6}$ analgesic, ${ }^{7}$ anti-inflammatory, ${ }^{8}$ antimicrobial, ${ }^{9}$ antiviral, ${ }^{10}$ antiparasitic, ${ }^{11}$ and anticancer. ${ }^{12}$ It is also reported that the benzimidazole derivatives exhibit significant activity against several viruses such as HIV and influenza. ${ }^{12}$ These derivatives have also been used to act as topoisomerase inhibitors. ${ }^{13}$ Several methods have been reported for the synthesis of benzimidazoles and bezothiazoles. ${ }^{14-17}$ More recently, transition metal-catalyzed amination followed by condensation has been reported for the preparation of various benzimidazoles. ${ }^{18,19 a}$ However, many of these methods have several limitations such as low yields, a special oxidation process, long reaction time, tedious work-up procedures, co-occurrence of several side reactions, and poor selectivity. The substitution of carboxylic acid or aldehyde component with an alternative functional group has not been widely reported. To the best of our knowledge, there are only very few reports on the synthesis of benzimidazole directly from alcohols. ${ }^{19 \mathrm{~b}-\mathrm{e}}$ Recently, Blacker et al. ${ }^{19 f}$ reported ruthenium-catalyzed hydrogen-transfer reactions (Scheme 1) for the conversion of alcohols into benzimidazoles under drastic conditions. Also Moorthy et al. ${ }^{19 g}$ reported the IBX mediated

\footnotetext{
* Corresponding authors. Tel.: +91 821 2412191/2419661; fax: +91 8212412191 .

E-mail addresses: kmantelingu@yahoo.com (K. Mantelingu), rangappaks@ gmail.com (K.S. Rangappa).
}

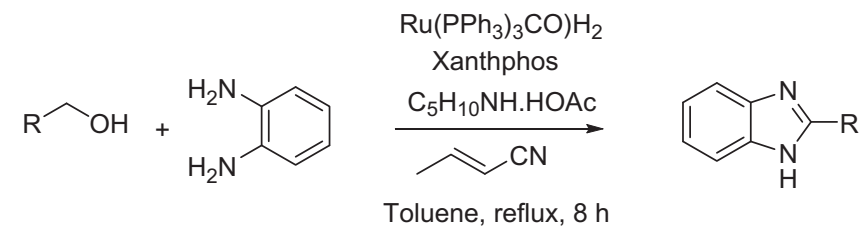

Scheme 1. Ruthenium-catalyzed synthesis of benzimidazoles.

synthesis of benzimidazoles from alcohols. However, no report has been found on the synthesis of benzothiazoles directly from alcohols. Also, IBX is not soluble in many organic solvents and explosive in nature. ${ }^{19 \mathrm{~h}}$ Very recently, our group has reported onepot synthesis of benzimidazoles from gem-dibromomethylarenes. ${ }^{20}$

In continuation of our work on the development of useful synthetic methodologies, ${ }^{21-23}$ in this study we report the use of ${ }^{\circledR} \mathrm{T} 3 \mathrm{P}$ as an oxidizing and cyclodehydrating agent for the synthesis of benzimidazole and benzothiazole derivatives under mild conditions. Propylphosphonic anhydride $\left({ }^{\circledR} \mathrm{T} 3 \mathrm{P}\right)$ functions both as coupling agent and water scavenger, ${ }^{24}$ offering several advantages such as high yields and purity, low toxicity, broad functional group tolerance, and easy work-up when compared to traditional reagents. Although ${ }^{\circledR} \mathrm{T} 3 \mathrm{P}$ has been mainly used as an effective and mild condensation reagent in peptide synthesis, new applications have been developed for this reagent, ${ }^{25}$ which include direct conversion of carboxylic acid into nitriles, dehydrations of amides to nitriles, formation of Weinreb amides, $\beta$-lactam synthesis, ester formation, alcohol oxidations, ${ }^{25 g, \mathrm{~h}}$ and preparation of heterocycles. ${ }^{25 \mathrm{i}}$ The 
Table 1

T3P-DMSO mediated synthesis of 1c under different reaction conditions

\begin{tabular}{rlllll}
\hline No. & Solvent & T3P $(50 \%)$ (equiv) & Time $(\mathrm{h})$ & Temperature $\left({ }^{\circ} \mathrm{C}\right)$ & Yield $^{\mathrm{a}} \%$ \\
\hline 1 & EtOAc & 1.0 & 8 & $0-25$ & 10 \\
2 & EtOAc & 1.5 & 8 & $0-25$ & 50 \\
3 & EtOAc & 2.0 & 4 & $0-25$ & 90 \\
4 & EtOAc & 2.5 & 4 & $0-25$ & 88 \\
5 & Toluene & 2.0 & 4 & $0-25$ & 75 \\
6 & $\mathrm{THF}$ & 2.0 & 6 & $0-25$ & 20 \\
7 & $\mathrm{CHCl}_{3}$ & 2.0 & 4 & $0-25$ & 50 \\
8 & $\mathrm{CH}_{3} \mathrm{CN}$ & 2.0 & 4 & $0-25$ & 60 \\
9 & $\mathrm{Acetone}$ & 2.0 & 4 & $0-25$ & Trace \\
10 & $\mathrm{CH}_{2} \mathrm{Cl}$ & 2.0 & 6 & $0-25$ & 30 \\
11 & EtOAc & 2.0 & 3 & 40 & 86 \\
12 & EtOAc & 2.0 & 2 & 50 & 73 \\
13 & EtOAc & 2.0 & 2 & 60 & 75 \\
14 & EtOAc & 2.0 & 1 & 70 & \\
\hline
\end{tabular}

a Isolated yield. diverse advantages and applications of ${ }^{\circledR} \mathrm{T} 3 \mathrm{P}$ show its potential as a reagent in organic synthesis. Though, ${ }^{\circledR} \mathrm{T} 3 \mathrm{P}$ has been identified as a mild water scavenger, the wider scope and synthetic utility of this reagent for oxidization and cyclodehydration has not been explored.<smiles>CCCP1(=O)OP(=O)(P=P)OP(=O)(P=P)O1</smiles>

" Structure of propylphosphonic anhydride $\left({ }^{\circledR} \mathrm{T} 3 \mathrm{P}\right) "$

Here, we report a novel, direct approach for synthesis of benzimidazoles and benzothiazoles starting from various alcohols, $o$-diamine, and $o$-aminothiophenol without the need for an additional oxidant. ${ }^{26}$ The tandem process involves oxidation, cyclization and ${ }^{\circledR} \mathrm{T} 3 \mathrm{P}$ mediated dehydrogenation under mild conditions at $0-25^{\circ} \mathrm{C}$ (Scheme 1$)$.

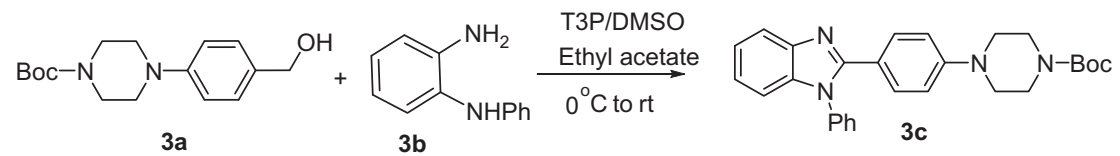

Scheme 2. General approach for the synthesis of benzimdazoles.

Table 2

Synthesis of benzimidazoles from alcohols, using 0 -diaminoarenes

\begin{tabular}{|c|c|c|c|c|c|}
\hline Entry $^{a}$ & Alcohol & Substrate & Product ${ }^{\mathrm{b}, \mathrm{c}}$ & Time (h) & Yield\% \\
\hline 1 & & $1 \mathrm{~b}$ & & 4 & 90 \\
\hline 2 & & $2 b$ & & 3 & 93 \\
\hline 3 & & $3 b$ & & 3 & 95 \\
\hline 4 & & & & 2.5 & 88 \\
\hline 5 & & & & 2.5 & 97 \\
\hline 6 & $\mathrm{Cl}$ & $1 \mathrm{~b}$ & & 2.5 & 92 \\
\hline 7 & & $1 \mathrm{~b}$ & & 3 & 94 \\
\hline 8 & & 3 & & 3 & 88 \\
\hline
\end{tabular}


Table 2 (continued)

\begin{tabular}{|c|c|c|c|c|}
\hline Entry $^{\mathrm{a}}$ & Alcohol & Product $^{\mathrm{b}, \mathrm{c}}$ & Time (h) & Yield\% \\
\hline 9 & & 1b ${ }^{\mathrm{NH}_{2}}$ & 4 & 85 \\
\hline 10 & $10 a$ & 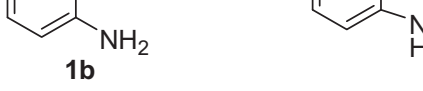 & 3 & 94 \\
\hline 11 & & $\begin{array}{l}\text { NHMe } \\
\text { 2b }\end{array}$ & 3 & 90 \\
\hline 12 & & 3b & 4 & 87 \\
\hline 13 & & $\mathrm{IH}_{2}$ & 2.5 & 94 \\
\hline 14 & & $14 b$ & 2.5 & 92 \\
\hline 15 & & $14 b$ & 4 & 85 \\
\hline 16 & $\mathrm{Cl}^{\prime}$ & $14 b$ & 2 & 93 \\
\hline 17 & & 14 & 2 & 95 \\
\hline 18 & & $14 b$ & 3 & 93 \\
\hline 19 & & & 3.5 & 91 \\
\hline 20 & 8 & $4 \mathrm{~b}$ & 3 & 90 \\
\hline
\end{tabular}

a ${ }^{\circledR}$ T3P (2 equiv) was used.

b Reaction time was 2.5-4 h.

c Purified by crystallization or column chromatography.

In order to explore the scope and optimal conditions for T3PDMSO mediated synthesis of benzimidazoles and benzothiazole, benzyl alcohol 1a was selected as a model. The reaction of 1a (1.1 equiv), 1,2-phenylenediamine ( 1.0 equiv), ${ }^{\circledR} \mathrm{T} 3 \mathrm{P}$ ( 2.0 equiv, $50 \%$ solution in EtOAc), and 2:1 volume of EtOAc:DMSO at
$0-25{ }^{\circ} \mathrm{C}$ for $4 \mathrm{~h}$ yielded $90 \%$ of $\mathbf{1 c}$ (Table 1 , entry 3 ). The influence of DMSO, various solvents and temperature on the synthesis of benzimidazole 1c was studied and the results are summarized in Table 1 . We tried the reaction 1a with $\mathbf{1 b}$ using ${ }^{\circledR} \mathrm{T} 3 \mathrm{P}$ ( 2.0 equiv) alone without DMSO both at $0-25^{\circ} \mathrm{C}$ and $70^{\circ} \mathrm{C}$ but no reaction 


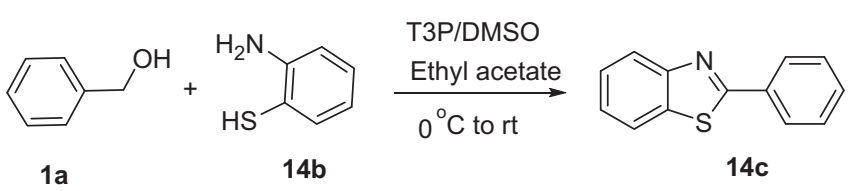

Scheme 3. General approach for the synthesis of benzothiazoles.

was observed. Increasing the volume of DMSO in the ratio (EtOAc/DMSO) to 1:1,1:2,1:3, and 1:4 did not improve the yield. The optimization studies of the experiments are provided in Table 1 , (entries 5-10) which shows the effect of various solvents such as EtOAc (entry 3, 90\%), toluene (entry 5, 75\%) and $\mathrm{CH}_{3} \mathrm{CN}$ (entry 8 , $60 \%$ ), in which ethyl acetate was chosen as the appropriate solvent with consideration to yield. The optimum temperature of the reaction was determined by conducting the experiments at 40 , 50,60 , and $70^{\circ} \mathrm{C}$. The results showed that at these temperatures the reaction time was drastically reduced, but with no significant increase in the yield of benzimidazole 1c.

The reactions were carried out using ethyl acetate at $0-25{ }^{\circ} \mathrm{C}$ by taking $1: 1.1 \mathrm{~mol}$ ratio mixture of $o$-phenylenediamine, and different alcohols in the presence of ${ }^{\circledR} \mathrm{T} 3 \mathrm{P}$ to get the desired product in excellent yield (Scheme 2) the results in Table 2 show that aromatic, aliphatic, and heterocyclic alcohols react without any significant difference to provide their corresponding benzimidazoles and benzothiazoles in good yield. This method can tolerate protecting group like Boc and other functional groups such as ester, halide, nitrile, allylic, and methoxy. The scope and the generality of this procedure is illustrated with respect to various aliphatic, aromatic, and heterocyclic alcohols and the results are summarized in Table 2.

To generalize our reagent system, the applicability of the ${ }^{\circledR} \mathrm{T} 3 \mathrm{P} /$ DMSO system was examined for their reactions with a series of aromatic, aliphatic, and heterocyclic alcohols with 1,2-phenylendiamines under the optimized conditions (Table 2). As shown, a variety of alcohols bearing electron-donating (entries 8-9) and electron withdrawing (entries 4-7), heterocyclic (10-11), and aliphatic (12-13) substituents were successfully employed to prepare the corresponding benzimidazole derivatives in excellent yields. This procedure is applicable to substituted 1,2-phenylenediamines, which produced the corresponding 2-arylbenzimidazoles simply in excellent yields. 2-Aminothiophenol also underwent the reaction, affording the corresponding 2-arylbenzothiazoles (Scheme 3) in excellent yields (Table 2, entries 14-20). The 2-amiophenol did not produce the desired products in the reaction.

In conclusion, we have developed an expedient and direct method for the synthesis of benzimidazoles and benzothiazoles in excellent yields, starting directly from a variety of alcohols 1,2-phenylenediamine and 2-aminothiophenol derivatives. The protocol involves ${ }^{\circledR} \mathrm{T} 3 \mathrm{P}-\mathrm{DMSO}$ mediated oxidation of alcohols to aldehydes followed by cyclocondensation with 1,2-phenylenediamine and $o$-aminothiolphenol, to afford benzimidazoles and benzothiazoles in one-pot operation with excellent yield. ${ }^{\circledR} \mathrm{T} 3 \mathrm{P}$ is low in toxicity, and commercially available at moderate price. The range of benzimidazoles and benzothiazoles were produced in high yields without the need for any additional oxidants.

\section{Acknowledgment}

The authors are grateful to the UGC, Govt., of India for financial support to K.M. for the projects vide No. F.No.39-710/2011 (SR) dated 21-01-2011.

\section{References and notes}

1. Tanious, F. A.; Hamelberg, D.; Bailly, C.; Czarny, A.; Boykin, D. W.; Wilson, W. D J. Am. Chem. Soc. 2004, 126, 143.

2. Kuhler, T. C.; Swanson, M.; Shcherbuchin, V.; Larsson, H.; Mellgard, B.; Sjostrom, J. E. J. Med. Chem. 1998, 41, 1777.

3. Mavrova, A.; Anichina, K. K.; Vuchev, D. I.; Tsenov, J. A.; Denkova, P. S.; Kondeva, M. S.; Micheva, M. K. Eur. J. Med. Chem. 2006, 41, 1412.

4. Kohara, Y.; Kubo, K.; Imamiya, E.; Wada, T.; Inada, Y.; Naka, T. J. Med. Chem. 1996, 39, 5228.

5. Mederski, W. W.; Dorsch, D.; Anzali, S.; Gleitz, J.; Cezanne, B.; Tsaklakidis, C. Bioorg. Med. Chem. Lett. 2004, 14, 3763.

6. Richards, M. L.; Lio, S. C.; Sinha, A.; Tieu, K. K.; Sircar, J. C. J. Med. Chem. 2004, 47, 6451.

7. Elmer, G. I.; Pieper, J. O.; Goldberg, S. R.; George, F. R. Psychopharmacology (Berl.) 1995, 117, 23.

8. Mader, M.; de Dios, A.; Shih, C.; Anderson, B. D. Bioorg. Med. Chem. Lett. 2008 $18,179$.

9. Arjmand, F.; Mohani, B.; Ahmad, S. Eur. J. Med. Chem. 2005, 40, 1103.

10. Gualtieri, F.; Brody, G.; Fieldsteel, A. H.; Skinner, W. A. J. Med. Chem. 1972, 15, 420.

11. Valdez, J.; Cedillo, R.; Hernandez-Campos, A.; Yepez, L.; Hernandez-Luis, F.; Navarrete-Vazquez, G.; Tapia, A.; Cortes, R.; Hernandez, M.; Castillo, R. Bioorg. Med. Chem. Lett. 2002, 12, 2221.

12. Tamm, I. Science 1957, 126, 1235.

13. Porcari, A. R.; Devivar, R. V.; Kucera, L. S.; Drach, J. C.; Townsend, L. B. J. Med. Chem. 1998, 41, 1251.

14. Imidazole and Benzimidazole Synthesis; Grimmett, M. R., Ed.; Academic Press: San Diego, 1997.

15. (a) Hornberger, K. R.; Adjabeng, G. M.; Dickson, H. D.; Davis-Ward, R. G. Tetrahedron Lett. 2006, 47, 5359; (b) Wang, R.; Lu, X. X.; Yu, X. Q.; Shi, L.; Sun, Y. J. Mol. Catal. A: Chem. 2007, 266, 198.

16. (a) Mukhopadhyay, C.; Tapaswi, P. K. Tetrahedron Lett. 2008, 49, 6237; (b) Lin C.; Lai, P. T.; Liao, S. K. S.; Hung, W.-T.; Yang, W.-B.; Fang, J.-M. J. Org. Chem. 2008, 73, 3848.

17. (a) Yang, D.; Fokas, D.; Li, J.; Yu, L.; Baldino, C. M. Synthesis 2005, 47; (b) Surpur, C. M.; Singh, P. R.; Patil, S. B.; Samant, S. D. Synth. Commun. 2007, 37, 1375

18. (a) Zou, B.; Yuan, Q.; Ma Angew. Chem., Int. Ed. 2007, 46, 2598; (b) Evindar, G.; Batey, R. A. Org. Lett. 2003, 5, 133.

19. (a) Curini, M.; Epifano, F. Synlett 2004, 1832; (b) Wilfred, C. D.; Taylor, R. J. K. Synlett 2004, 1628; (c) Ruiz, V. R.; Corma, A.; Sabater, M. J. Tetrahedron Lett. 2010, 66, 730; (d) Kondo, T.; Yang, S.; Huh, K. T.; Kobayashi, M.; Kotachi, S.; Watanabe, Y. Chem. Lett. 1991, 1275; (e) Kim, J. W.; He, J.; Yamaguchi, K.; Mizuno, N. Chem. Lett. 2009, 62, 1275; (f) Blacker, A. J.; Farah, M. M.; Hall, M. I.; Marsden, S. P.; Saidi, O.; Williams, J. M. Org. Lett. 2009, 11, 2039; (g) Moorthy, J. N.; Neogi, I. Tetrehedron Lett. 2011, 52, 3868; (h) Plumb, B.; Harper, D. J. Chem. Eng. News 1990, 3.

20. Chandrappa, S.; Vinaya, K.; Ananda Kumar, C. S.; Rangappa, K. S. Tetrhedron Lett. 2010, 51, 6493.

21. Raghavendra, G. M.; Harsha, K. B.; Vinaya, K.; Mantelingu, K.; Rangappa, K. S. Synth. Commun. 2011, 41, 2296.

22. Revanna, C. N.; Swaroop, T. R.; Raghavendra, G. M.; Bhadre Gowda, D. G.; Mantelingu, K.; Rangappa, K. S.; J. Heterocycl. Chem. in press, doi:00880.

23. Chandrappa, S.; Vinaya, K.; Ramakrsihanappa, T.; Rangappa, K. S. Synlett 2010 , 20, 3019.

24. Llanes Garcia, A. L. Synlett 2007, 1328.

25. (a) Burkhart, F.; Hoffmann, M.; Kessler, H. Angew. Chem., Int. Ed. 1997, 36, 1191; (b) Zumpe, F. L.; Melanie, F.; Schmitz, K.; Lender, A. Tetrahedron Lett. 2007, 48, 1421; (c) Augustine, J. K.; Atta, R. N.; Ramappa, B. K.; Boodappa, C. Synlett 2009 3378; (d) Augustine, J. K.; Vairaperumal, V.; Narasimhan, S.; Alagarsamy, P.; Radhakrishnan, A. Tetrahedron 2009, 65, 9989; (e) James, M.; Crawforth, J. M.; Paoletti, M. Tetrahedron Lett. 2009, 50, 4916; (f) Basavaprabhu, N. N.; Ravi, S. L.; Sureshbabu, V. V. Tetrehedron. Lett. 2010, 51, 3002; (g) Meudt, A.; Scherer. S. Böhm, C. PCT Int. Appl. WO 2005102978, 2005.; (h) Chem. Abstr. 2005, 143 440908.; (i) Augustine, J. K.; Sharmila, V. V.; Alagarsamy, N. P.; Radhakrishnan, A. Tetrahedron 2009, 65, 9989.

26. General procedure for the one-pot synthesis of benzimidazoles and benzothiazoles: to a solution of alcohol $(1.1 \mathrm{mmol})$ in a mixture of solvents ethyl acetate $(4 \mathrm{~mL})$ and DMSO $(2 \mathrm{~mL})$, was added ${ }^{\circledR} \mathrm{T} 3 \mathrm{P}(2 \mathrm{mmol}, 50 \%$ solution in ethyl acetate) at $0{ }^{\circ} \mathrm{C}$ and the resulting reaction mixture was stirred at room temperature for $1-2 \mathrm{~h}$ under nitrogen atmosphere. The reaction was monitored by TLC, 1,2-phenylenediamine $(1 \mathrm{mmol})$ was added and stirred further for $1-2 \mathrm{~h}$. After completion of the reaction, the mixture was diluted with water $(20 \mathrm{~mL})$ and neutralized with $10 \% \mathrm{NaHCO}_{3}$ solution. The product was extracted with ethyl acetate $(10 \mathrm{~mL})$ and the combined organic phase was washed with water $(10 \mathrm{~mL})$ and brine solution. The organic phase was dried over anhydrous $\mathrm{Na}_{2} \mathrm{SO}_{4}$. The solvent was dried under reduced pressure to afford a crude product, which was purified on silica gel using ethyl acetate and petroleum ether. For the conversion of alcohols to benzothiazoles the same procedure as above was followed except the use of $o$-aminothiophenol, instead of 1,2-phenylenediamine. 